\title{
The dynamics of the occurrence of pea leaf weevil (Sitona lineatus L.) on pea and faba bean crops on selected localities in Wielkopolska
}

\section{Dynamika występowania oprzędzika pręgowanego (Sitona lineatus L.) na uprawach grochu siewnego i bobiku na wybranych stanowiskach w Wielkopolsce}

\author{
Przemysław Strażyński
}

\section{Summary}

The aim of the study was to assess the severity of the occurrence of pea leaf weevil (Sitona lineatus L.) on varieties of pea (Milwa, Tarchalska, Model) and faba bean (Amulet, Nadwiślański) throughout the vegetation period. The field experiment was conducted in 2011-2012 in Wielkopolska region (Winna Góra, Karśnice). The beetles were collected by entomological sweep net (100 strokes), at weekly intervals. Pea leaf weevil occurred abundantly on each pea variety and the highest number was recorded on the variety Tarchalska, while Amulet appeared to be more attractive faba bean variety.

Key words: pea, faba bean, Pea Leaf Weevil, Sitona lineatus

\section{Streszczenie}

Celem badań była ocena nasilenia występowania oprzędzika pręgowanego (Sitona lineatus L.) na odmianach grochu siewnego (Milwa, Tarchalska, Model) i bobiku (Amulet, Nadwiślański) przez cały okres wegetacji roślin. Doświadczenie polowe prowadzono w latach 2011-2012 w Wielkopolsce (Winna Góra, Karśnice), metodą czerpakowania (100 uderzeń), w tygodniowych odstępach. Stwierdzono liczne występowanie chrząszczy na każdej z odmian grochu - największą liczebność notowano na odmianie Tarchalska, natomiast bardziej atrakcyjną odmianą bobiku była odmiana Amulet.

Słowa kluczowe: groch, bobik, oprzędzik pręgowany, Sitona lineatus

Instytut Ochrony Roślin - Państwowy Instytut Badawczy

Zakład Entomologii

Władysława Węgorka 20, 60-318 Poznań

P.Strazynski@iorpib.poznan.pl 


\section{Wstęp / Introduction}

Oprzędziki (Sitona) to chrzązcze z rodziny ryjkowcowatych (Curculionidae), spośród których wiele gatunków notowanych jest jako ważne gospodarczo szkodniki roślin. Także $\mathrm{w}$ uprawach roślin bobowatych stanowią istotne zagrożenie, zwłaszcza w okresie wschodów roślin, z uwagi na specyfikę uszkodzeń i intensywność żerowania dorosłych chrząszczy po przezimowaniu. Znaczne uszkodzenia powodowane przez oprzędziki w tym okresie mogą być przyczyną wyraźnego obniżenia plonu (Wiech 1977). Szacuje się, że w sprzyjających warunkach (sucha i ciepła pogoda) ubytki powierzchni liściowej w wyniku żerowania oprzędzików, prowadzące do spadku plonu, mogą sięgać kilkunastu procent (George 1962; Wnuk i Wiech 1985; Cantot i wsp. 1993; Williams i wsp. 1995), a przy licznym wystąpieniu obniżki plonu nasion grochu mogą dochodzić nawet do 25\% (Bournoville 1991). Pokolenie letnie również uszkadza liście, jednak $\mathrm{z}$ uwagi na stadium wegetacji roślin nie powoduje już tak poważnych strat, jak wiosną. Niemniej dobre warunki rozwoju w tym okresie powodują wzrost liczebności chrząszczy przed okresem zimowania, a powodowane przez nie uszkodzenia zwiększają podatność roślin na porażanie przez patogeny chorobotwórcze.

Oprzędzik pregowany (Sitona lineatus L.) jest dominującym gatunkiem oprzędzika $\mathrm{w}$ uprawach roślin bobowatych, a głównymi żywicielami tego gatunku jest groch i bobik (Hans 1959; Ruszkowska 1961; Wnuk i Wiech 1996).

Celem badań była ocena dynamiki występowania chrzaszzczy $S$. lineatus na wybranych odmianach grochu siewnego i bobiku w pełnym okresie wegetacji roślin.

\section{Materiały i metody / Materials and methods}

Badania prowadzono w latach 2011-2012, w Wielkopolsce, w miejscowościach: Winna Góra i Karśnice. Doświadczeniem objęto uprawy polowe grochu siewnego - odmiany: Milwa, Tarchalska, Model oraz bobiku - odmiany: Amulet i Nadwiślański. Dorosłe chrząszcze oprzę- dzika pręgowanego odławiano metodą czerpakowania (próbę stanowiło 100 uderzeń po przekątnej uprawy). Odłowy prowadzono w tygodniowych odstępach, w okresie od wschodów (faza 5 liści, BBCH 15) do około dwóch tygodni przed zbiorami.

\section{Wyniki i dyskusja / Results and discussion}

W każdej z lokalizacji, pierwsze chrząszcze $S$. lineatus na grochu stwierdzano $\mathrm{w}$ obydwu latach badań w połowie kwietnia, natomiast na bobiku o tydzień później. Wiosną obserwowano stopniowy wzrost liczebności chrząszczy. W okresie wschodów roślin liczebność nie przekraczała 10 osobników w jednej próbie. Szczyt nasilenia występowania przypadał $\mathrm{w}$ okresie pojawiania się nowego pokolenia, pod koniec kwitnienia i później. W końcowych fazach wegetacji roślin obserwowano stopniowy spadek liczebności chrząszczy, choć utrzymywała się ona nadal na stosunkowo wysokim poziomie (rys. 1-5). Oprzędziki w tym okresie znacznie uszkadzały liście, na których stwierdzono, co prawda nieliczne, ogniska infekcji grzybowych, zwłaszcza na odmianach bobiku.

Z badanych odmian grochu największą liczebność chrząszczy odłowiono na odmianie Tarchalska. Na odmianie bobiku Amulet zanotowano o 8,4\% w 2011 r. i o 12,1\% w 2012 r. więcej osobników niż na odmianie Nadwiślański. We wcześniejszych badaniach wskazywano, że odporność odmian bobiku na porażenie przez oprzędziki może wynikać z zawartości tanin, przede wszystkim w okresie wschodów (Ropek i Kulig 2009), a przy wyborze pokarmu przez oprzędzika pręgowanego decydująca rolę pełnią bodźce smakowe (Wnuk i Wiech 1983). Zaobserwowano także istotny wpływ warunków pogodowych na liczebność szkodnika. Przebieg pogody był także czynnikiem kluczowym w obserwacjach Wnuka i Wiecha (1980), badających intensywność żerowania oprzędzików na odmianach grochu (masę zjedzonych liści przypadająca na jednego chrząszcza). Sezon 2011 był wyraźnie bardziej korzystny dla rozwoju oprzędzików (ciepło i sucho) stwierdzono średnio na grochu o $12 \%$, a na bobiku o 18,6\% więcej osobników niż w sezonie 2012.

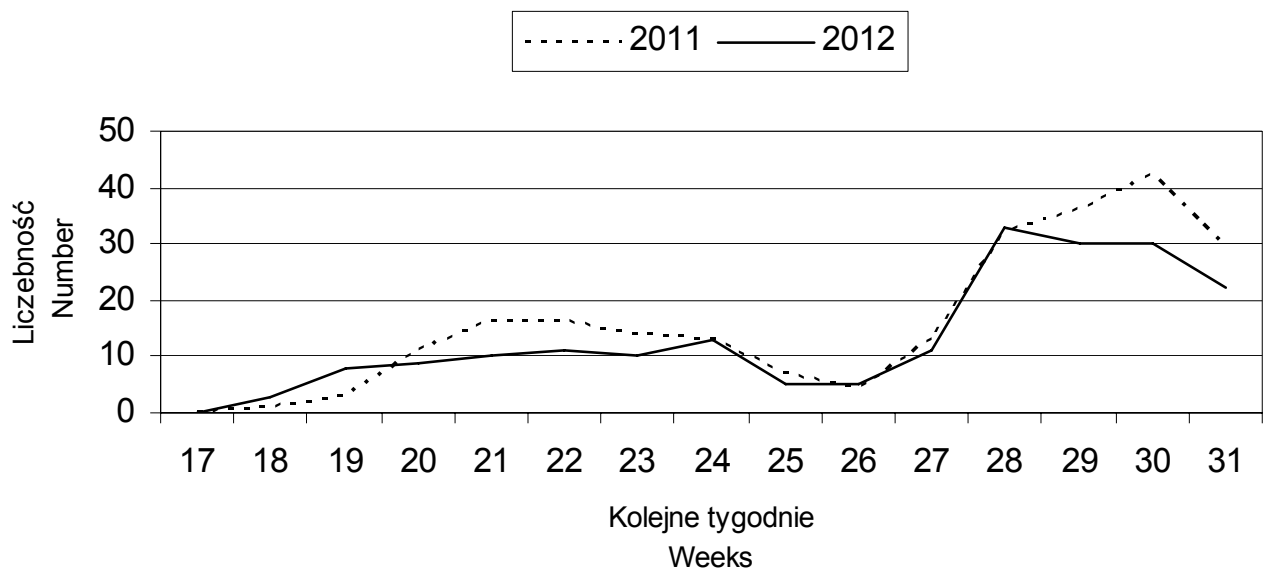

Rys. 1. Dynamika liczebności S. lineatus na grochu odmiana Milwa w Winnej Górze, w latach 2011-2012

Fig. 1. Number dynamice of S. lineatus on pea variety Milwa in Winna Góra, in 2011-2012 


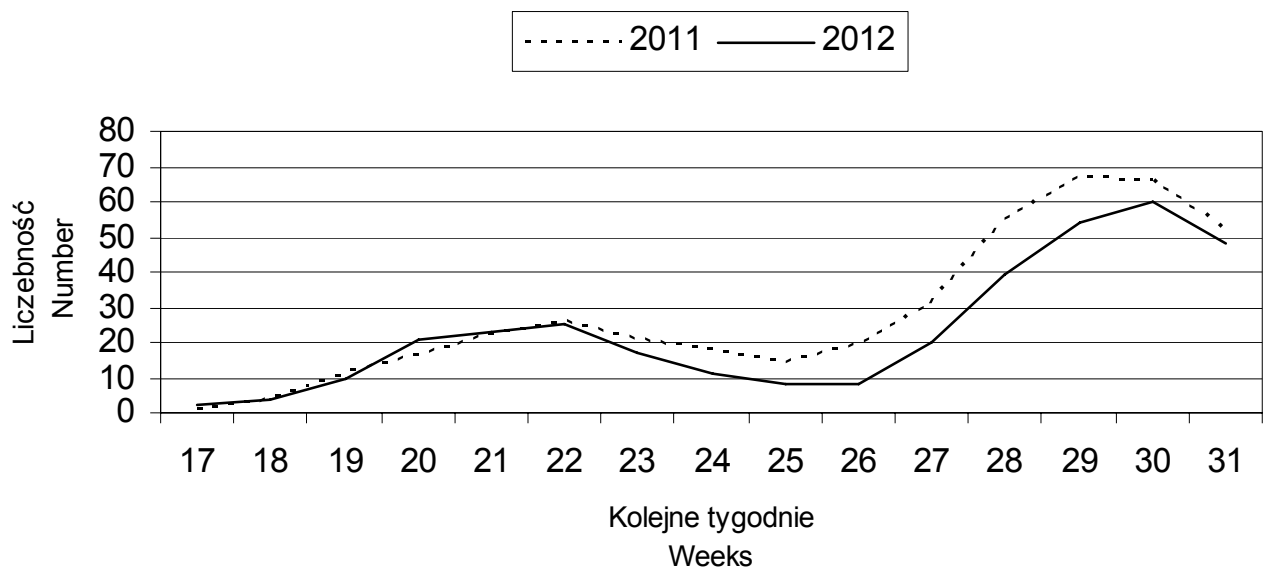

Rys. 2. Dynamika liczebności S. lineatus na grochu odmiana Tarchalska w Karśnicach, w latach 2011-2012

Fig. 2. Number dynamice of S. lineatus on pea variety Tarchalska in Karśnice, in 2011-2012

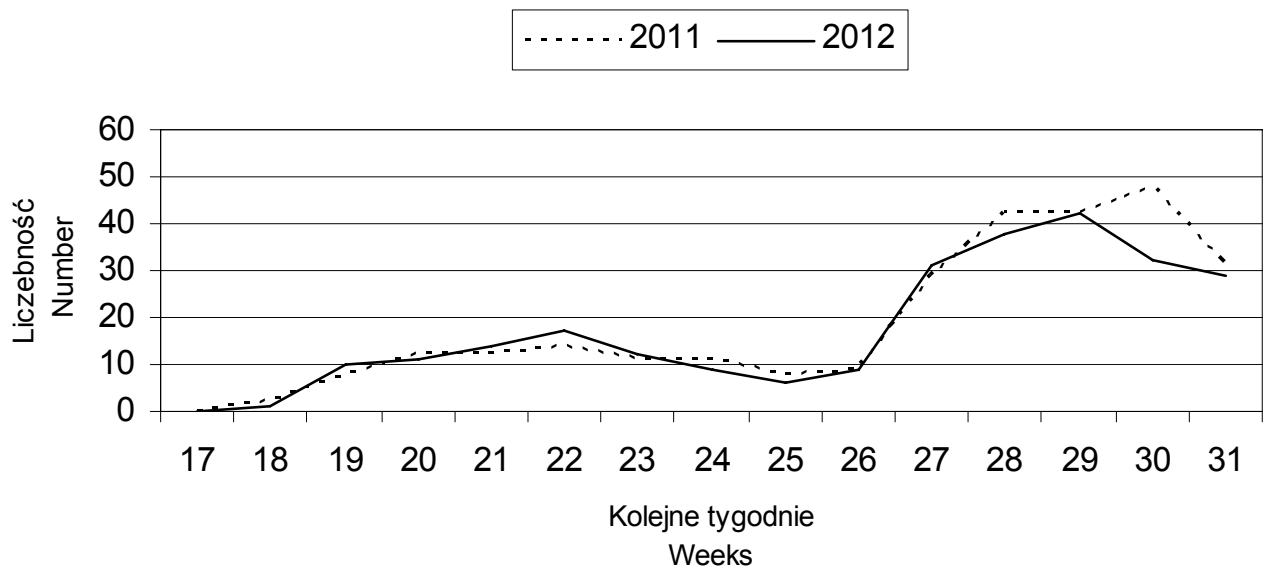

Rys. 3. Dynamika liczebności S. lineatus na grochu odmiana Model w Winnej Górze, w latach 2011-2012

Fig. 3. Number dynamice of S. lineatus on pea variety Model in Winna Góra, in 2011-2012

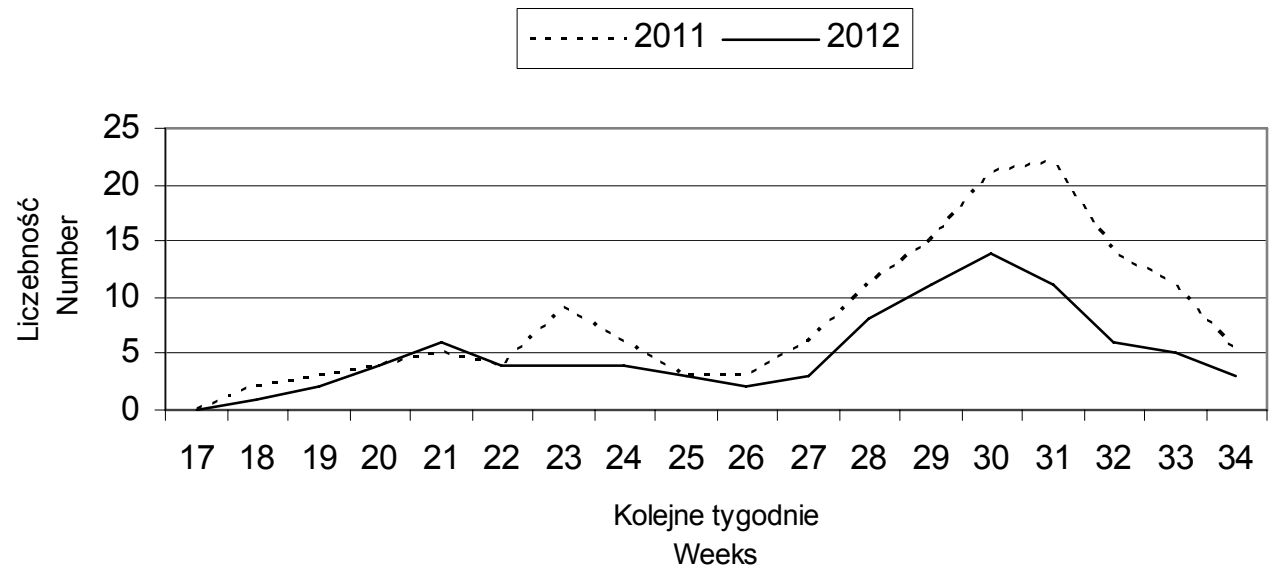

Rys. 4. Dynamika liczebności S. lineatus na bobiku odmiana Amulet w Winnej Górze, w latach 2011-2012

Fig. 4. Number dynamice of $S$. lineatus on faba bean variety Amulet in Winna Góra, in 2011-2012 


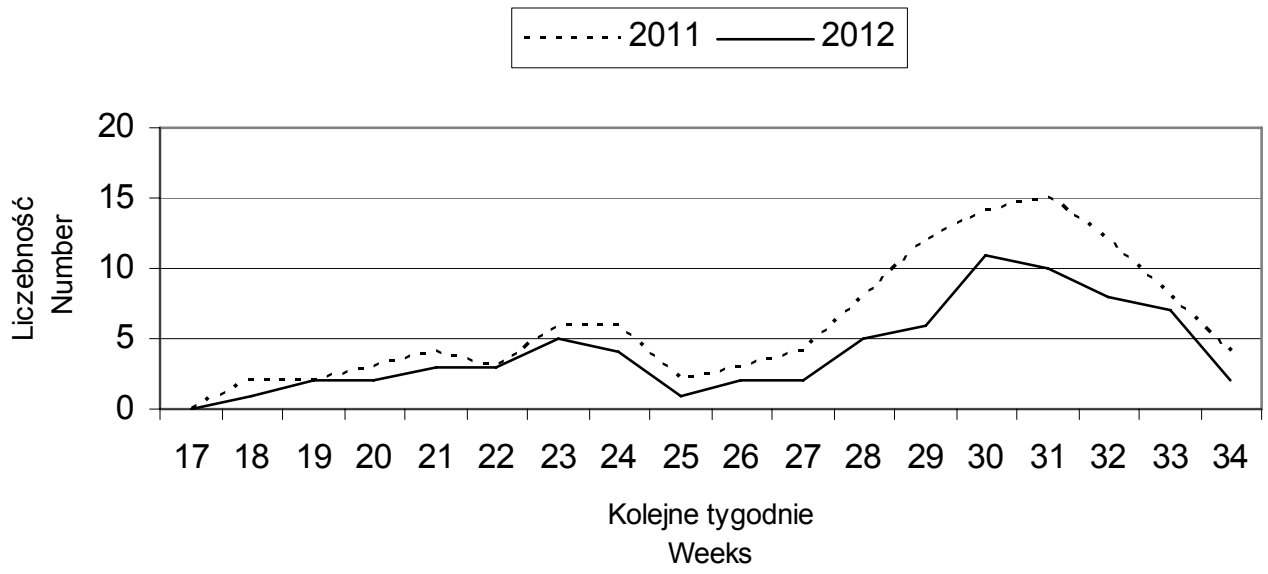

Rys. 5. Dynamika liczebności S. lineatus na bobiku odmiana Nadwiślański w Winnej Górze, w latach 2011-2012

Fig. 5. Number dynamice of $S$. lineatus on faba bean variety Nadwiślański in Winna Góra, in 2011-2012

Ochrona chemiczna istotnie wpływa na obniżenie stopnia uszkodzenia bobiku przez oprzędziki (Ropek i Kulig 2001). W prowadzonym doświadczeniu w trakcie odłowów zauważono, że chrząszcze oprzędzików wykazują dużą płochliwość i spadają z roślin podczas zbliżania czerpaka. Z kolei doświadczenia prowadzone przez Wiecha (1977) wykazały obecność chrząszczy w dużej liczebności również na powierzchni gleby oraz ukryte w grudkach, w bliskości roślin. Zjawisko to może być przyczyną niedostatecznych efektów podczas chemicznych zabiegów zwalczania oprzędzika.

\section{Wnioski / Conclusions}

1. Zarówno odmiany grochu, jak i bobiku były w różnym stopniu atrakcyjne dla chrząszczy $S$. lineatus, niemniej może stanowić on zagrożenie na plantacjach obydwu upraw.

2. Niskotaninowa odmiana bobiku Amulet była w większym stopniu zasiedlana przez chrząszcze $S$. lineatus $\mathrm{W}$ porównaniu $\mathrm{z}$ wysokotaninową odmianą Nadwiślański.

\section{Literatura / References}

Bournoville R. 1991. Des rèsultats recent sur les insects nuisibles. Perspect. Agric. 164: 73-77.

Cantot P., Taupin P., Hacquet J. 1993. Maîtriser le sitone du pois. Bull. Semences 122: 34-37.

George K. 1962. The effect of artificial defoliation of pea plants on the yield of shelled peas. Plant Pathol. 2 (2): 73-80.

Hans H. 1959. Beitrage zur Biologie von Sitona lineatus (L.). Z. Angew. Entomol. 44: 343-386.

Ropek D., Kulig B. 2001. Wpływ agrotechniki i chemicznej ochrony na stopień uszkodzenia bobiku przez owady. [Influence of agricultural practices and chemical protection of field bean on the degree of damages caused by pests]. Prog. Plant Prot./Post. Ochr. Roślin 41 (2): 399-401.

Ropek D., Kulig B. 2009. Podatność odmian bobiku o zróżnicowanej zawartości tanin na szkodniki. [Susceptibility of faba bean cultivars with different tannin content to pests]. Prog. Plant Prot./Post. Ochr. Roślin 49 (1): 134-137.

Ruszkowska I. 1961. Z obserwacji nad występowaniem oprzędzików - Sitona spp. Pol. Pismo Entomol., Seria B, 3-4 (23-24): 209-215.

Wiech K. 1977. Ocena szkodliwości oprzędzika pręgowanego Sitona lineatus L. (Col., Curculionidae). Ann. Agric. Fenn. 9: $139-197$.

Williams L., Schotzko D.J., O'Keeffe L.E. 1995. Pea leaf weevil herbivory on pea seedlings: effects on growth response and yield. Ent. Exp. Appl. 76: 255-269.

Wnuk A., Wiech K. 1980. Podatność odmian grochu na uszkodzenia przez postacie dorosłe oprzędzików, Sitona spp. (Coleoptera, Curculionidae). Pol. Pismo Entomol. 50: 599-605.

Wnuk A., Wiech K. 1983. Preferencja odmian grochu przez oprzędzika pręgowanego - Sitona lineatus (L.) (Col. Curculionidae) w warunkach laboratoryjnych. Pol. Pismo Entomol. 53: 217-225.

Wnuk A., Wiech K. 1985. Wpływ rozstawy rzędów na występowanie i żerowanie szkodników grochu w uprawie na ziarno. Acta Agr. Silv., Ser. Agrar. 24: 227-235.

Wnuk A., Wiech K. 1996. Sitona weevils (Coleoptera: Curculionidae) feeding on pea (Pisum sativum L.). Pol. Pismo Entomol. 65: $73-81$. 